\section{El Fraile Villamor}

\section{Por Romualdo Cabrales $O$.}

\section{De Bogotá}

Un distinguido médico que lleva en sus venas sangre del ilustre naturalista Francisco Antonio Zea, el compañero de Nariño en la conspiración de 1794; el que de prisionero en España pasó á Director del Jardín Botánico; el Presidente del primer Congreso Republicano, después Vicepresidente de la Gran Colombia y su brillante Ministro en Europa; ese médico, cuya pluma se desliza como un pez vivo en manos de una virgen del Funza, describe así la psicología del estudiante de medicina colombiano:

"Curiosa, á la vez que irónica y amarga, es la psicología de los estudiantes de medicina. Vienen del claustro del Bachillerato rebosantes de dicha; repleto el cerebro de logomaquías y filosofías que nada valen en el curo de nuestra vida azarosa; con la cabeza poblada de ensueños de clientelas opulentas, descubrimientos inauditos, altos puestos sociales, y salen al cabo de los años con un aire de austeridad y de melancolia que los acompaña hasta la muerte. El contacto forzoso con el dolor proteiforme, la vida en las salas de anatomía y en el hospital; los ayes y lamentos, la permanencia entre atmósferas saturadas de olores medicamentosos, el ácido fénico, el yodoformo, los vendajes, las operaciones presenciadas en las mesas de cirugía cuando las cavidades esplágnicas exponen al aire las vísceras palpitantes y sangrientas; todo eso va operando lenta pero definitivamente la total transformación de su naturaleza en otra desencantada y triste. Y salen después al pugilato del ejercicio profesional, en estos tiempos de plétora en que la asistencia se presta á cambio de honorarios irrisorios y en que la lucha por los enfermos elimina las almas delicadas y sensibles." (1)

Hoy, cuando festeja la Patria su primer Centenario de Independencia, no es exótico recordar aquí el nombre de un Fraile de los tiempos coloniales, generoso y benefac- tor no solamente del pobre sino de la juventud amiga de sorprender los secretos de la materia. El fundó los claustros en que se han formado los hombres de ciencia colombianos, naturalistas y médicos; los que bajo esas vetustas arcadas han empezado la vida tan notablemente descrita por Luis Zea Uribe. Por esta consideración vamos á insertar aquí unas líneas en honor del Fraile, que puede llamarse, sin vacilaciones, el Precursor de los médicos patriotas.

"En atención á lo reducido del Hospital San Pedro, fundado á espaldas de la Catedral por el primer Arzobispo de Bogotá, Fray Juan de los Barrios, se pensó desde entonces en construír uno apropiado al efecto.

"Un Fraile distinguido de San Juan de Dios, natural de Bogotá, que había estudiado medicina en los Hospitales de Cartagena y Panamá, recibió como Prior el Real Convento de Hospitalarios; el mismo edificio que se conoce desde entonces con el nombre de Hospital de San Juan de Dios, con el objeto de establecer allí el hospital de la ciudad con más amplitud que el de San Pedro, que fue trasladado al moderno. El Padre Villamor recogió cuantiosas limosnas y empleó sus propios bienes y el dinero producido por la venta del Hospital San Pedro para construír el nuevo edificio que se levantó sobre los planos del nuevo hospital de Granada en España y con el espacio necesario para el servicio de doscientas camas para enfermos de ambos sexos.

"El altruista Padre Villamor no alcanzó á ver terminado el edificio, al que dedicó su fortuna y los mejores esfuerzos de su vida. Tiene el Fraile bogotano el honor de haber trabajado en una obra grandiosa para los atrasados tiempos coloniales."

"De las cátedras y de los viejos claustros del hospital fueron arrancados en 1816 por los jefes pacificadores Morillo y Enrile, por el delito de ser patriotas, los muy conocidos médicos de los primeros años de la República. Ya el Doctor Pedro Fermín de Vargas, conspirador con Nariño y con Zea en 1794, se había perdido

(I) Del libro inédito La Medicina y la Cirugía en Colombia por el Doctor Pedro M. Ibáñez y dos estudiantes de medicina: 1908. 
en las Antillas, pero la Heroica había alumbrado á José Fernández Madrid, el último Presidente en 1816; y los Doctores Juan María Pardo, que firmó el acta de la Independencia el 20 de Julio, José Félix Merizalde, médico Coronel de los Ejércitos patriotas; y Miguel Ibáñez, Benito Osorio, Manuel María Quijano y J.J. García eran asistentes forzados de los hospitales militares españoles. Entre ellos se contaba y merece especial mención el estudiante de medicina Rafael Mendoza, después soldado ilustre y mutilado, que alcanzó el grado de General de los Ejércitos Libertadores. CURIOSA, A LA VEZ QUE IRONICA, Y AMARGA ES LA PSICOLOGÍA DE LOS ESTUDIANTES DE MEDICI-
NA, como fecunda en Próceres médicos ha sido el hospital de San Juan de Dios.” (1)

¿Y ahora? Allá en la Clínica Externa que dirige el modesto sabio Doctor Pompilio Martínez, envuelto en la penumbra, apenas se dibuja un cuadro al óleo con la siguiente bárbara inscripción:

El $\mathrm{M}^{\mathrm{I}} \mathrm{R}^{\mathrm{DO}} \mathrm{P}^{\mathrm{E}} \mathrm{P}^{\mathrm{I}}$ Pedro Pablo DE Billamor Religioso Preb $^{\text {ro }}$ DE NRA orden Primer Fundador Dste Nuebo Conbt $^{\circ}$ I digno DE Memoria Por su Religioso Selo y Birtual Fallesio A 5 DE Agosto EL año DE 1729.

Bogotá, 12 de Julio, 1910.

\section{SAL HEPATICA \\ Una combinaclón admirable \\ PARA CORhBEGIR LA TORPBZA HEPATIGA, \\ DISOLVRR EL ACINO UFICO y BKTOHAR EL TUBO DIGESTIVO}

Toda persona que viva en los tropicos debe usar csta preparación si quiere conservar el hígado en buen estado. Los médicos lo aconsejan y aquellos que no lo hagan deben hacerlo si tienen interés en estar en primera línea de su profesión.
De venta en todas las Boticas
Pídanse muestras á BRISTOL, MYERS C.॰
277-278 Greene Ave. Brooklyn. New York,
Al haceor ol podido húgase referencia al Rkapartorro.

Reproducción del aviso publicado en Repertorio de Medicina y Cirugía volumen II Número 5 de febrero 15 de 1911.

\footnotetext{
( I) Del libro citado.
} 